Journal of Applied Pharmaceutical Science Vol. 7 (01), pp. 214-216, January, 2017

Available online at http://www.japsonline.com

DOI: $10.7324 / J A P S .2017 .70132$

ISSN 2231-3354 (cc)) BY-NC-SA

\title{
Penfluridol Induced Extrapyramidal symptoms (EPS): A Case Report
}

\author{
Sereen Rose Thomson, Balaji Ommurugan, Shalini Adiga ${ }^{*}$, Navin Patil, Saurish Reddy \\ Department of Pharmacology, Kasturba Medical College, Manipal Campus, Manipal University, Karnataka - 576104, India.
}

\section{ARTICLE INFO \\ Article history: \\ Received on: 21/09/2016 \\ Revised on: 13/11/2016 \\ Accepted on: 03/12/2016 \\ Available online: $31 / 01 / 2017$}

\section{Key words:}

Typical antipsychotics, extrapyramidal symptoms, adverse drug reaction, refractory schizophrenia.

\begin{abstract}
Penfluridol is a long acting oral antipsychotic agent taken once a week for the treatment of schizophrenia and other psychotic disorders. The weekly dosage regimen of the drug makes it an ideal drug in non-compliant patients, which is commonly seen in 50-75\% of psychotic disorder patients. Better compliance may be associated with fewer relapses, better quality of life, fewer crises and less or shorter hospitalizations, leading to lower costs. As a part of pharmacovigilance program of India, we hereby report a case of Penfluridol induced extrapyramidal symptoms in a patient with refractory schizophrenia who developed EPS even at the least possible dose of the drug. Relevant data was collected from case record as per Central Drug Standard Control Organisation form and causality, severity and preventability assessment was done as per Naranjo's, Hartwigs and Schumock and Thornton scales respectively.
\end{abstract}

\section{INTRODUCTION}

Schizophrenia is one of the major mental health problems of our time. It is prevalent worldwide affecting $1 \%$ of population and its incidence in India is about 2-3 per 1000 . The illness has substantial short-term and long-term consequences with severe distress and variety of social and occupational impairments for the individual as well as the family in association with severe medical disorders and mortality. Onset of symptoms usually occurs in late adolescence or early adulthood with women affected more than men (Gautam et al., 2015). Antipsychotic medications represent the first line treatment for patients with schizophrenia and have been the mainstay of treatment since the 1950s. The pharmacological mechanism of development of extrapyramidal symptoms (EPS) seems to be a relative dopamine deficiency on the basis of a striatal dopamine

* Corresponding Author

Shalini Adiga, Professor and Head,Department of Pharmacology, Kasturba Medical College, Manipal Campus, Manipal University, Karnataka, India-576104. Email: shalini.adiga @ manipal.edu
D2-receptor occupancy and a relative acetylcholine excess. Apart from the EPS-inducing effect, the D2 antagonistic affinity has been considered to be the main antipsychotic property of first-generation antipsychotics. Usually these are dose dependent and reversible. Non-adherence and non-compliance are one of the major problems associated with typical antipsychotics due to the above mentioned side effect (Lee, 2007).

Penfluridol, a diphenylbutylpiperidine derivative is a long acting depot preparation and can be administered once a week for better compliance and symptom control. Incidence of EPS is less with penfluridol at a weekly dose of 160-200 mg (Soares and Lima, 2006).

Hereby we report a case of Penfluridol induced EPS in a patient with refractory schizophrenia.

\section{CASE REPORT}

A previously normotensive and premorbidly normal 61year-old lady presented to the Psychiatry outpatient department (OPD) in October 2015 with a history of delusion of persecution, third person auditory hallucinations and thought broadcast. 
Further inquiry revealed that the above symptoms were a manifestation of an exacerbation of her underlying condition, paranoid schizophrenia with which she had been diagnosed 15 years back. The details of her treatment history were sketchy due to lack of patient documents. On admission, routine investigations were carried out and was found to be normal. Hence, she was started on oral fostera (olanzapine $5 \mathrm{mg}+$ fluoxetine $20 \mathrm{mg}$ ), paliperidone $1.5 \mathrm{mg}$, nitrazepam $5 \mathrm{mg}$ and trihexyphenidyl $2 \mathrm{mg}$. After 1 month of treatment with the above medications, patient along with her relatives presented to the OPD with a history of noncompliance to medication associated with a relapse of symptoms. Therefore, she was tried on depot preparation of haloperidol and flupenthixol, but developed restlessness and tremors (EPS) within a period of 1 week, with a Barnes Akathisia score of 5. However symptoms of EPS improved on stopping the drug and treatment with a central anticholinergic agent trihexyphenidyl $4 \mathrm{mg}$. Our patient was now diagnosed as a case of refractory schizophrenia due to non-compliance to both typical and atypical class of drugs and also due to a decline in her Brief Psychiatric Rating Scale (BPRS) score. She was then started on oral penfluridol $40 \mathrm{mg}$ weekly from $25^{\text {th }}$ of November 2015 , but within a period of 1 week (December 2nd) she presented with bilateral upper limb cog wheel rigidity and tremors. A complete physical examination revealed reduced blink rate, poor self-care, and CNS examination revealed bilateral tremors in upper limbs and other parts of the body, cog wheel rigidity with brisk reflexes. After a detailed work up, a probable diagnosis of penfluridol induced EPS was thought of and drug was withdrawn, after ruling out other possibilities for EPS. As patient was non-compliant to other oral antipsychotics, penfluridol was reintroduced on December $7^{\text {th }} 2015$ at a dose of $20 \mathrm{mg}$. However, within a period of 1 week (December $14^{\text {th }}$ ), she developed akathisia, bilateral upper limb tremors and rigidity. EPS was treated using a central anticholinergic trihexyphenidyl, and penfluridol was then tried at doses of $10 \mathrm{mg}$ and $5 \mathrm{mg}$ for 1 week each. Patient developed EPS in the form of parkinsonism, even at the least possible dose of Penfluridol $(5 \mathrm{mg})$. Hence, the drug was withdrawn and EPS was treated using trihexyphenidyl $8 \mathrm{mg}$. She was then later started on olanzapine $5 \mathrm{mg}$ along with anticholinergic trihexyphenidyl $6 \mathrm{mg}$. Patient and relatives were educated regarding the use of medications and after a period of 1 month her symptoms reduced with better compliance.

\section{DISCUSSION}

The American Psychiatric Association currently recommends that selection of an antipsychotic medication should be based on a patient's previous responses to the drug and its sideeffect profile (Lehman et al., 2010). Patients on maintenance therapy who take neuroleptics irregularly are particularly at high risk for psychotic decompensation. Striatal D2 receptor antagonism is the critical element in the EPSs produced by these drugs.
Non-compliance to antipsychotic medications accounts to about 20 to $40 \%$. The poor level of compliance can be due to various causes which includes adverse effects due to medications, medicine viewed as persecutory, negation of the disease, lack of social support, complexity of the prescription and the relapse of the disease. Compliance is thus influenced by the patient's clinical features, local provision of health care and the specific nature of the drug (Llorca et al., 2005). Long-acting injectable antipsychotics have better therapeutic compliance and thus better efficacy. Several studies have shown a significant improvement in compliance related to the pharmaceutical formulation of antipsychotics. Hospitalization and relapse risks are lower in compliant than in non-compliant patients.

Penfluridol, a first generation antipsychotic acts on the dopaminergic system by blocking the dopamine type 2 (D2) receptors (Soares and Lima, 2006). This mechanism, however, may lead to a variety of extrapyramidal symptoms (EPS) (such as tremor, slurred speech, akathisia, and dystonia) some of which appear after long-term exposure (tardive dyskinesia) (Panda AK et al., 2014). Studies have shown that penfluridol safely controls schizophrenic symptoms when administered on a weekly basis (Llorca et al., 2005).

The major advantage with Penfluridol is that it can be given as a weekly oral depot preparation and also patients can avoid the discomfort of daily oral medication and fortnightly injection (Vaidyalingam, 1990). Penfluridol, in a weekly oral dose of 20 to $60 \mathrm{mg}$, maintains the level of improvement previously achieved by long acting injectable and short acting oral neuroleptics (Soares BGO and Lima MS., 2006). However the probable causes of EPS at lower doses of penfluridol could be as follows:

1. Keepers \& Casey have found that the risk of EPS was greatest at intermediate to low doses. It has been proposed that with intermediate doses near complete blockade of central dopamine receptors occurs and further dose increase may thus not affect the dopamine system further. On the other hand, Garver et al. suggested that EPS may result from compensatory cholinergic and dopaminergic hyperactivity when dopamine blockade is incomplete (Casey and Daniel, 1991).

2. Patient factors: Risk factors in our patient were: age (elderly), gender (females), cognitive deficit. Asian race has also been implicated as a risk factor for EPS and has demonstrated an increased incidence of EPS when given similar neuroleptic doses (Divac et al., 2014). In general, blacks are considered to be slow metabolizers. Low body weight and slow metabolism may increase the plasma concentration of drugs causing side effects even at lower doses.

3. History of prior EPS: Patients who have experienced EPS with prior neuroleptic treatment are vulnerable to further EPS. If this information is available, it is thought that recurrence risk of EPS can be reliably predicted with $75-85 \%$ accuracy (Divac et al., 2014). 


\section{CONCLUSION}

In our case Penfluridol was introduced at a dose of 40mg weekly but within a period of 1 week she developed EPS. So Penfluridol was stopped and was reintroduced at doses of $20 \mathrm{mg}$, $10 \mathrm{mg}$ and $5 \mathrm{mg}$ and patient developed EPS at every dose. Finally drug was withdrawn and EPS was treated using a central anticholinergic trihexyphenydyl.

Causality is crucial for risk benefit assessment as it causes an establishment of a relationship between the drug and the adverse event itself. Causality as per Naranjo's scaling was found to be probable (Naranjo et al 1981). Severity and preventability assessment as per Hartwig's scale and Schumock and Thornton scale were found to be moderately severe and definitely preventable (Raut et al., 2012).

\section{Financial support and sponsorship: Nil.}

Conflict of Interests: There are no conflicts of interest.

Informed Consent: Written informed consent was obtained from the patient and relatives for publication of this case.

\section{REFERENCES}

Casey, Daniel E. Neuroleptic drug-induced extrapyramidal syndromes and tardive dyskinesia. Schizophr Res 1991; 4: 109-120.

Divac N, Prostran M, Jakovcevski I, and Cerovac N. SecondGeneration Antipsychotics and Extrapyramidal Adverse Effects. BioMed Research International, 2014, Article ID 656370, 6 pages, 2014. doi:10.1155/2014/656370.

Gautam S et al. 2015. Clinical Practice Guidelines for Psychiatrists in India. (ONLINE). Available at http://www.indianpsychiatricsociety.org/pdf/CPG_Schizophrenia_Depress ion_Disorder.pdf. (Accessed 1st September 2016).
Lee HJ. Pharmacogenetic Studies Investigating the Adverse Effects of Antipsychotics. Psychiatry Investig 2007;4:66-75

Anthony F. Lehman, Jeffrey A. Lieberman, Lisa B. Dixon, Thomas H. McGlashan, Alexander L. Miller, Diana O. Perkins, Julie Kreyenbuhl. 2010. Practice guideline for the Treatment of Patients with Schizophrenia. (ONLINE). Available at https://psychiatryonline.org/pb/assets/raw/sitewide/practice_guidelines/gui delines/schizophrenia.pdf (Accessed 1st September 2016)

Llorca PM, Miadi-Fargier H, Lançon C, Jasso Mosqueda G, Casadebaig F, Philippe A, Guillon P, Mehnert A, Omnès LF, Chicoye A, Durand-Zaleski I. Cost-effectiveness analysis of schizophrenic patient care settings: impact of an atypical antipsychotic under long-acting injection formulation. Encephale 2005; 31:235-46 [Article in French].

Naranjo CA, Busto U, Sellers EM, Sandor P, Ruiz I, Roberts EA, Janecek E, Domecq C, Greenblatt DJ. A method for estimating the probability of adverse drug reactions. Clin Pharmacol Ther 1981; 30:23945 .

Panda AK, Bala K, Bhirud L. Extrapyramidal syndrome. BMJ Case Rep 2014. doi:10.1136/bcr-2013-009752

Raut A, Patel P, Patel C, Pawar A. Preventability, Predictability and Seriousness of Adverse Drug Reactions amongst Medicine Inpatients in a Teaching Hospital: A Prospective Observational Study. Int J Pharm Chem Biol Sci 2012; 1: 1293-1299

Soares BGO, Lima MS. Penfluridol for schizophrenia. Cochrane Database of Systematic Reviews 2006, Issue 2. Art. No.: CD002923. doi: 10.1002/14651858.CD002923.pub2.

Vaidyalingam N. Evaluation of penfluridol in hospitalized chronic schizophrenic. J Postgrad Med 1990; 36:100.

\section{How to cite this article:}

Thomson SR, Ommurugan B, Adiga S, Patil N, Reddy S. Penfluridol Induced Extrapyramidal symptoms (EPS): A Case Report. J App Pharm Sci, 2017; 7 (01): 214-216. 